\title{
Comparative study of gas diffusion in subsurface using dual-gas tracer $\mathrm{SF}_{6}$ and halon 1211
}

\author{
Weixian Wang ${ }^{a}$, Zongyu Gan, Yuan Yuan, Guoqing Zhou \\ Northwest Institute of Nuclear Technology, 710024 XI'AN, China
}

\begin{abstract}
Field experiment and soil column test were performed to study the gas diffusion in the soil subsurface using dual-gas tracer SF6 and halon 1211. Gas samples collected from pre-set sampling sites were measured. These two tracer gases showed the similar trend. At the different directions from injecting site, concentrations increased rapidly at the beginning, the peak value concentration of SF6 was higher than that of halon 1211, implied SF6 diffuse further. At the different depth from injecting site, tracer gases preferred to transport horizontal or downwards rather than upwards, meant gravity settling was an important factor affecting the gas diffusion. The effect of temperature and water content on the gas diffusion revealed that gases migrated fast obviously with the temperature increase, the change of water content had influence slightly. Gas desorption test indicated that much more halon 1211 was adsorbed on the soil, which led the diffusion process slow down.
\end{abstract}

\section{Introduction}

Gas phase diffusion through the unsaturated soil system arouses great scientific interest. The purpose of this study was to compare the diffusion behavior of $\mathrm{SF}_{6}$ and halon 1211 in soil subsurface, provide a simple method to determine the effective gas diffusion coefficient. Through in situ and soil column test, understanding the factors affect the gas migration, predicting gas diffusive transport. The in-situ method avoids the considerable uncertainties pertained to estimate apparent diffusion coefficient. A model accounting for simplified instantaneous point source also is presented and compared with the experimental data, the agreement is good. Both $\mathrm{SF}_{6}$ and halon 1211 are greenhouse gas, however, $\mathrm{SF}_{6}$ possess the highest Global Warming Potential, Considering the long lifetime for $\mathrm{SF}_{6}$ in the atmosphere, this results showes halon 1211 could be used as tracer instead of $\mathrm{SF}_{6}$.

\section{Materials and methods}

\subsection{Tracer gases and instrument}

$\mathrm{SF}_{6}$ (C.P. grade) was purchased from BeiFeng gases company with a purity of $99.9 \%$. Halon 1211 (C.P. grade, purity of $99.0 \%$ ) was purchased from ZheJiang Blue-Sky chemical-engineer company. $\mathrm{SF}_{6}$ and halon 1211 were measured using a gas chromatograph (Agilent6890, USA) equipped with a micro-cell electron capture detector $(\mu$ ECD). The GC parameters are presented as following: a column (length $2.4 \mathrm{~m}$, diameter $1 / 8 \mathrm{in}$.) packed with 80 -
100 mesh 5 A molecular sieve were used to separate $\mathrm{SF}_{6}$ and halon 1211, the carrier gas was ultra-pure $\mathrm{N} 2(99.999 \%)$ with a flow rate of $20 \mathrm{~mL} / \mathrm{min}$; the detector temperature was set at $300^{\circ} \mathrm{C}$; the column temperature was set at $90^{\circ} \mathrm{C}$ an air actuated gas sampling valve fitted with a $1 \mathrm{~mL}$ sample loop had been used to inject gas.

\subsection{Field experiment}

To carry out the present investigation, a field experiment was conducted at a meadow site in northwest China, at which grass was permitted to grow without grazing, mowing or fertilization. The soil has an initial $\mathrm{pH}$ value 7.7 and consists of $6.2 \%$ clay, $56.3 \%$ silt and $37.5 \%$ sand, the organic carbon and water content is $6.8 \mathrm{~g} \mathrm{~kg}-1$ and $12 \%$, respectively.

A hole with a diameter $8 \mathrm{~cm}$ and depth $2 \mathrm{~m}$ was excavated using Luoyang shovel, a hollow steel probe with a inner diameter $1 \mathrm{~mm}$ and length $2.2 \mathrm{~m}$ was emplaced into the hole bottom and backfilled with soil, which was used as injection hole. The lower end of the probe was filled with glass wool to prevent soil particle from entering the probe. After injecting the pure SF6 and halon 1211 each $25 \mathrm{~mL}$ at local atmospheric pressure using gas-tight syringe, the upper end was sealed. Soil gas samples had been collected periodically at different sampling sites with the hollow steel probe. The schematic diagram of injecting and sampling together with soil column was shown in Fig. 1. Taking note of that the sampling site at depth $1 \mathrm{~m}$ also represented the sampling site at north $1 \mathrm{~m}$.

\footnotetext{
a Corresponding author: wiges@sina.com
} 


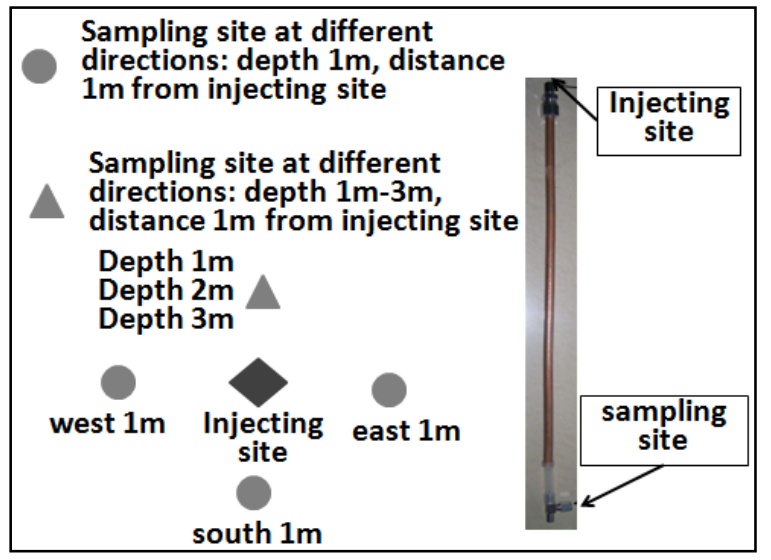

Figure 1. The schematic diagram of in-situ experiment and soil colimn.

\subsection{Soil column study}

Experiment was designed to determine the effect of temperature and water content on the gas phase diffusion. Desorption of $\mathrm{SF}_{6}$ and halon 1211 on the soil was also performed in the soil column.

The soil sample was collected from the experimental field at depth of $1 \mathrm{~m}$. The moist soil was air-dried, sieved to less than 100 mesh and stored at $20{ }^{\circ} \mathrm{C}$ before usage. The soil column device was made up of a copper tube with an exterior diameter of $9.5 \mathrm{~mm}$, an interior diameter of $9 \mathrm{~mm}$ and a length of $400 \mathrm{~mm}$. After the soil sample was packed, the one end of the column was fitted with a nut, at which a septum was held for injecting tracer gas. The other end was filled with glass wool and connected with open hose, from which the diffusive gas could be taken by tight syringe.

\section{Results and discussion}

\subsection{Gas diffusion at different directions in the soil}

The concentrations of tracer gases at four directions were measured and plotted as a function of time in Fig. 2. Two gases showesd the same trend. Both concentration of $\mathrm{SF}_{6}$ and halon 1211 increased rapidly at the beginning, the peak value reached at about $30 \mathrm{~h}$ approximately, which was 1.8 ppmv for $\mathrm{SF}_{6}$ and 1.3 ppmv for halon 1211 , respectively. The lower peak value of halon 1211 (about $30 \%$ less than that of $\mathrm{SF}_{6}$ ) suggested that it possessed the lower diffusive ability. After about $34 \mathrm{~h}$, the concentrations of two gases dropped slowly with measurement time.

The concentration shape showed little difference at four directions, which meant the soil subsurface was near homogeneous approximately, there was no preferential path for gas migration. However, there was dramatic concentration fluctuation at 21-30 h and $70 \mathrm{~h}$, this phenomenon may mainly result from continuous raining. When much water flushed, the soil pore may be clogged, the soil gas dissolved in the water or substituted by the water and migrated downward, which led the concentration falling fast in the sampling site.
McNerney[1] reported that the mercury vapour stopped volatizing in the soil subsurface after a big raining, which is consonant with our results.
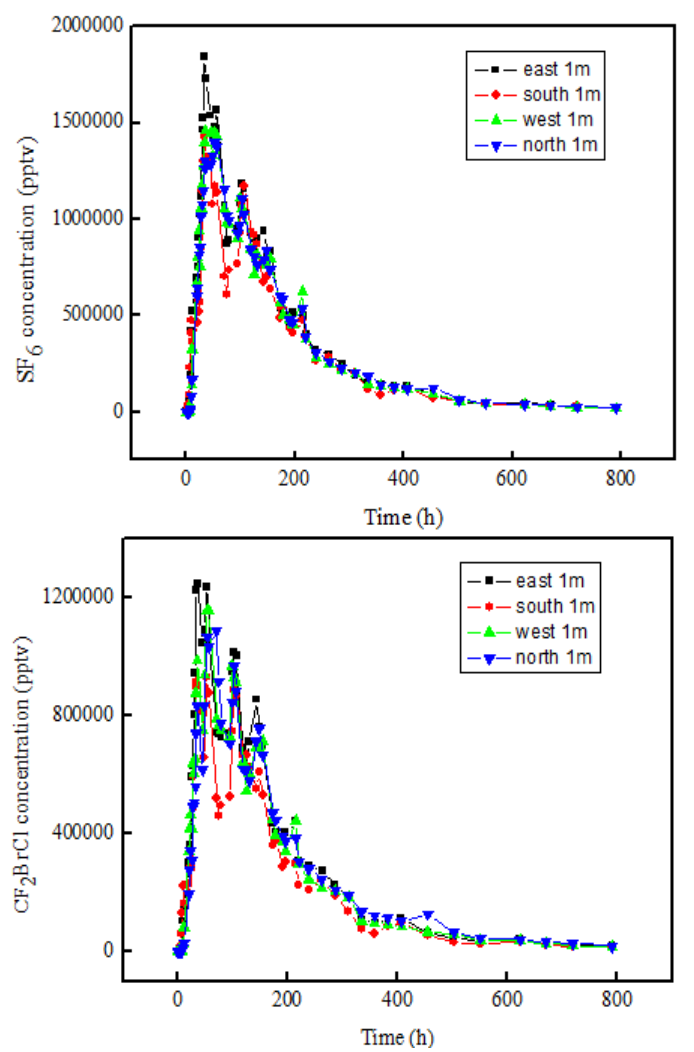

Figure 2. Concentration of $\mathrm{SF}_{6}$ and halon 1211 versus time at four directions.

\subsection{Gas diffusion at different depths in the soil}

At different depths, the concentrations of two tracer gases versus time were shown in Fig.3.

Two tracer gases also showed the similar trend. The peak value arrived at the same time about $30 \mathrm{~h}$ after injecting the pure gases. The concentrations at depth $2 \mathrm{~m}$ and $3 \mathrm{~m}$ were obviously higher than that of depth $1 \mathrm{~m}$. The result indicated that the gas preferred to transport horizontal or downwards rather than upwards. Compared with the air, the molecular weight of the two gases is 5-6 times bigger. Due to gravity settling, two gases were inclined to migrate downwards and concentrated. Craig[2] reported the heavier gas was more easily concentrated at the bottom of the polar ice cap.

The equation (5) was used to calculate the soil factor $\lambda$ and the effective diffusion coefficient $D_{e}$. As mentioned above, the gravity settling lower the gas upwards diffusion for the heavier gas, so the parameters were calculated respectively. To avoid the influence of raining, the data were selected from the sampling site at depth 2 $\mathrm{m}$ at $10 \mathrm{~h}$ and $34 \mathrm{~h}$. For the gas diffusion horizontal or downwards, concentrations were $2.17 \times 10^{6} \mathrm{pptv}, 3.80 \times 10^{6}$ pptv for $\mathrm{SF}_{6}$, and $1.38 \times 10^{6} \mathrm{pptv}, 3.30 \times 10^{6} \mathrm{pptv}$ for halon 1211 , respectively. The back calculated parameters $\lambda$ and $D_{e}$ were 0.43 and $2.05 \times 10^{-6} \mathrm{~m}^{2} \mathrm{~s}^{-1}$ for $\mathrm{SF}_{6}, 0.53$ and $1.81 \times 10^{-6} \mathrm{~m}^{2} \mathrm{~s}^{-1}$ for halon 1211. For the gas diffusion upwards, the calculated parameters $\lambda$ and $D_{e}$ were 1.38 
and $1.06 \times 10^{-6} \mathrm{~m}^{2} \mathrm{~s}^{-1}$ for $\mathrm{SF}_{6}, 1.96$ and $8.10 \times 10^{-7} \mathrm{~m}^{2} \mathrm{~s}^{-1}$ for halon 1211 .
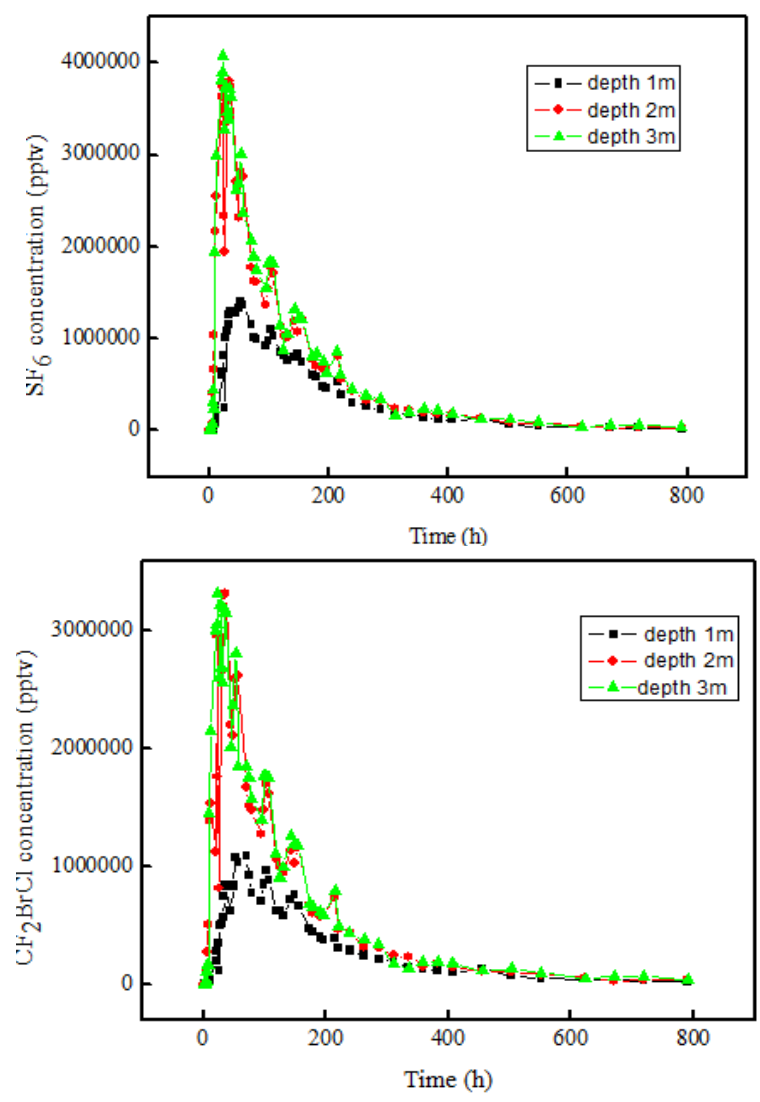

Figure 3. Concentration of $\mathrm{SF}_{6}$ and halon 1211 versus time at different depths

Using the instantaneous point source model and obtained parameters to calculate the concentration at the sampling site. Fig.3. showed the model results together with the determined concentrations. The agreement is good (some determined data were not shown for dramatic concentration fluctuation caused by raining). The model predicted the concentration shape, which matched the observed value approximately.

\subsection{The effect of temperature and water content}

In the soil column test, $\mathrm{SF}_{6}$ and halon 1211 mixed gases with the concentration $6 \mathrm{ppmv}$ each $0.5 \mathrm{~mL}$ was injected using tight syringe. The temperature was controlled at $22^{\circ} \mathrm{C}$ and $27^{\circ} \mathrm{C}$ by air-condition to study the effect of the temperature. The soil samples were prepared by adding the weight content of $2 \%$ and $5 \%$ water and the temperature was set at $22^{\circ} \mathrm{C}$ to study the effect of the water content. The results are shown in Fig. 4.

It could be seen that the effluent gases concentration rised as expected with temperature increasing from $22^{\circ} \mathrm{C}$ to $27^{\circ} \mathrm{C}$. The peak value changed from $3900 \mathrm{pptv}$ to $30000 \mathrm{pptv}$ for $\mathrm{SF}_{6}$ and $800 \mathrm{pptv}$ to 4400 pptv for halon 1211, which enlarged 5-8 times. It also should be pointed out that the difference between the peak values of the two gases, suggesting that $\mathrm{SF}_{6}$ diffuse much faster in the soil.
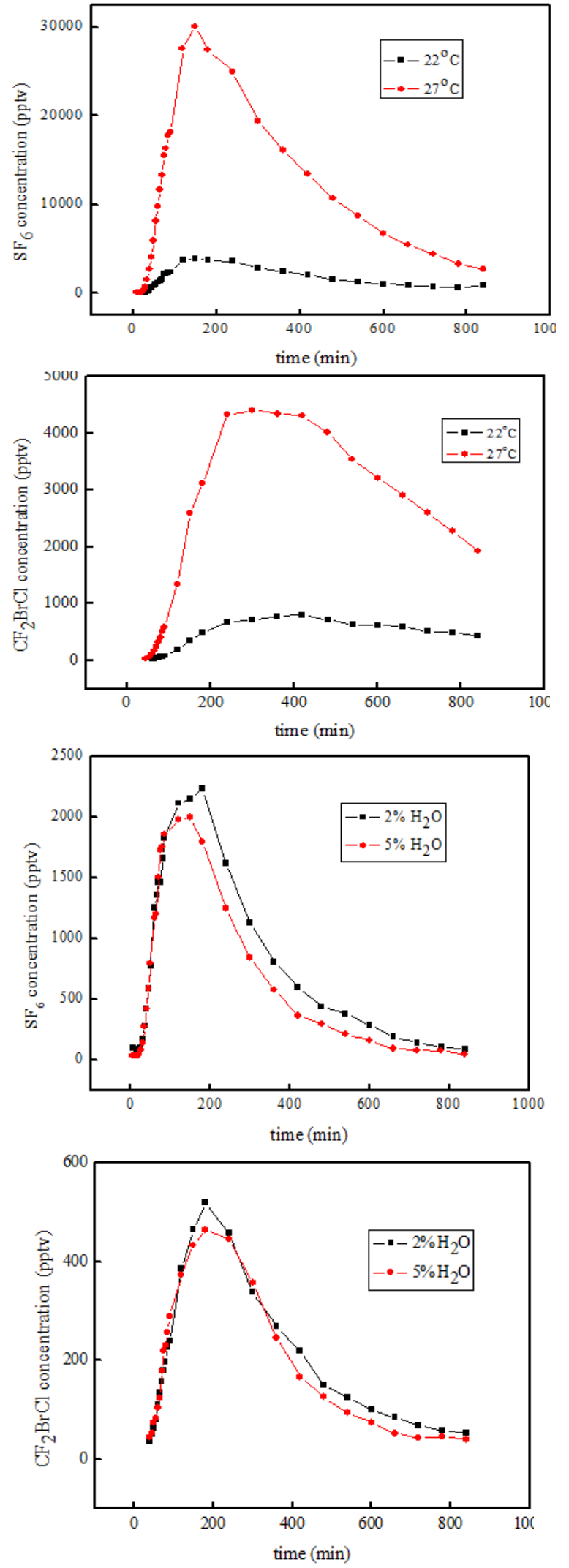

Figure 4. The effect of temperature and water content on the gas diffusion

The effect of the water content was less obvious. When the water content increased, the water molecular would occupy the more soil pore and enhance the distribution of gas among the water, which leads to the gas concentration dropping. As for $\mathrm{SF}_{6}$ and halon 1211, solubility in water was negligible. The effluent gases 
concentration dropped slightly with the water content increasing from $2 \%$ to $5 \%$.

\subsection{Gas desorption from the soil}

The results from the field experiment showed that $\mathrm{SF}_{6}$ could migrate further than that of halon 1211 under the same condition. This difference may be related to the adsorption of gas on the soil. $\mathrm{He}[3]$ reported that soil/air partition coefficient for trichloroethylene was different and mainly affected by the organic material content in the selected soils (yellow, paddyfield and black soil). Engesgaard[4] studied the diffusion of CFCs on the soil and found that the soil could block CFCs migration. Rattary[5] performed $\mathrm{SF}_{6}$ adsorption experiment on different materials, the result showed that gypsum cement had little adsorption ability on $\mathrm{SF}_{6}$, while the material which rich in zeolite minerals could adsorb $\mathrm{SF}_{6}$ easily.

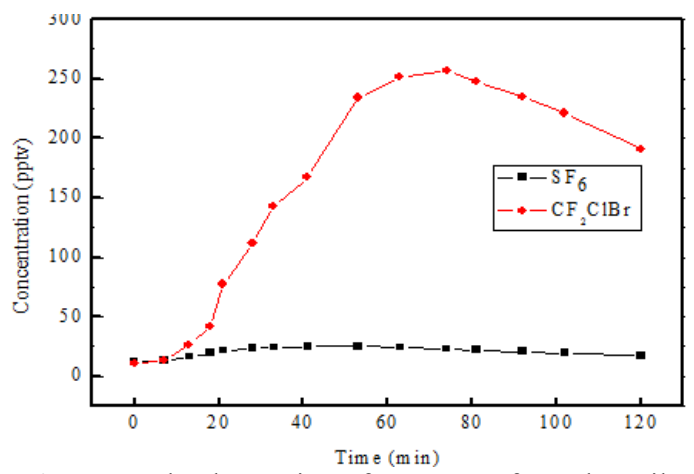

Figure 5. The desorption of two gases from the soil

In present work, the soil column test was conducted to compare the tracer gases adsorption ability. $\mathrm{SF}_{6}$ and halon 1211 mixed gases with the concentration 6 ppmv each 0.5 $\mathrm{mL}$ was injected, the temperature was set at $22^{\circ} \mathrm{C}$. After $24 \mathrm{~h}$, the effluent gas concentration was near the background. Heating the column with the IR lamp, the temperature was around $120^{\circ} \mathrm{C}$, the effluent gas was analyzed. The concentrations of two gases were plotted as a function of effluent time and shown in Fig. 5.

It is clear that much more halon 1211 was adsorbed on the soil and its effluent concentration was two times higher than the background. The soil also could adsorb $\mathrm{SF}_{6}$ slightly. This adsorption would affect the gas migration, especially for halon 1211 , which led to the diffusion process slow down obviously.

\section{Conclusions}

Field experiments and soil column tests were performed to investigate the gas diffusion in the soil subsurface using two tracer gases. To this scope, the concentrations on different directions and depths were determined, the effect of temperature and water content on the gas diffusion were examined. To simulate the gas concentration shape in the soil, an instantaneous point source model was proposed. The parameters (defined) to estimate are (1) the soil factor, and (2) the effective diffusion coefficient. Based on the results obtained in this work, the main conclusions were outlined below.
Two tracer gases showed the similar trend at different directions in the soil. Concentrations increased rapidly at the beginning, the peak value concentration of $\mathrm{SF}_{6}$ was higher than that of halon 1211, suggested that $\mathrm{SF}_{6}$ migrate further. At raining period, gas in the soil subsurface would be diluted greatly, which led the concentration falling fast in the sampling site.

At different depths, tracer gases concentration shapes revealed that the heavily gas preferred to transport horizontal or downwards rather than upwards. The results demonstrated the gravity settling was an important factor affecting the gas diffusion. As for the gas diffusion horizontal or downwards, $\lambda$ and $D e$ were 0.43 and $2.05 \times 10^{-6} \mathrm{~m}^{2} \mathrm{~s}^{-1}$ for $\mathrm{SF}_{6}, 0.53$ and $1.81 \times 10^{-6} \mathrm{~m}^{2} \mathrm{~s}^{-1}$ for halon 1211. For the gas diffusion upwards, $\lambda$ and $D e$ were 1.38 and $1.06 \times 10^{-6} \mathrm{~m}^{2} \mathrm{~s}^{-1}$ for $\mathrm{SF}_{6}, 1.96$ and $8.10 \times 10^{-7} \mathrm{~m}^{2} \mathrm{~s}$ ${ }^{1}$ for halon 1211 . The model predicted the concentration shape, which matches the observed value well.

With the temperature increasing, gases migrated much fast; the change of water content had slight influence on the gas diffusion, due to both $\mathrm{SF}_{6}$ and halon 1211 were low soluble in water. Desorption of gas from the soil indicated that much more halon 1211 was adsorbed on the soil. This adsorption affected the gas migration, which led to the diffusion process slow down. The simulation model did not consider the adsorption of gas on the soil and gravity settling, should be perfect in the future work.

\section{References}

1. Mcnemey J J, Buseck P R. Geochemical exploration using mercury vapour. Econ Geo, 1973, 68 (8), 1313-1320.

2. Craig H, Horibe Y, Sowers T. Gravitational separation of gases and isotopes in polar ice caps. Science, 1988, 242(4886), 1675-1678.

3. He Xin, Zhao Hui, Chen Shuo, Zhao Yazhi, Quan Xie. Influence of temperature on soil/air partitioning of trichloroethylene in soil in the northeast of china. Environmental Chemistry, 2007, 26 (3), 298-301.

4. Peter Engesgaard. Transport and time lag of chlorofluorocarbon gases in the unsaturated zone, rabis creek, denmark. Vadose zone, 2004, 3(4), 12491261.

5. Rattray. Adsorption of sulfur hexafluoride(abstract). NWWA annual meeting and exposition educational program, 1989, 30 Oct.-1 Nov., Houston, TX,27(1),728. 